\title{
Author Spotlight: Nikki Duong
}

Nikki Duong ${ }^{1}$

Published online: 4 May 2020

(c) Springer Science+Business Media, LLC, part of Springer Nature 2020

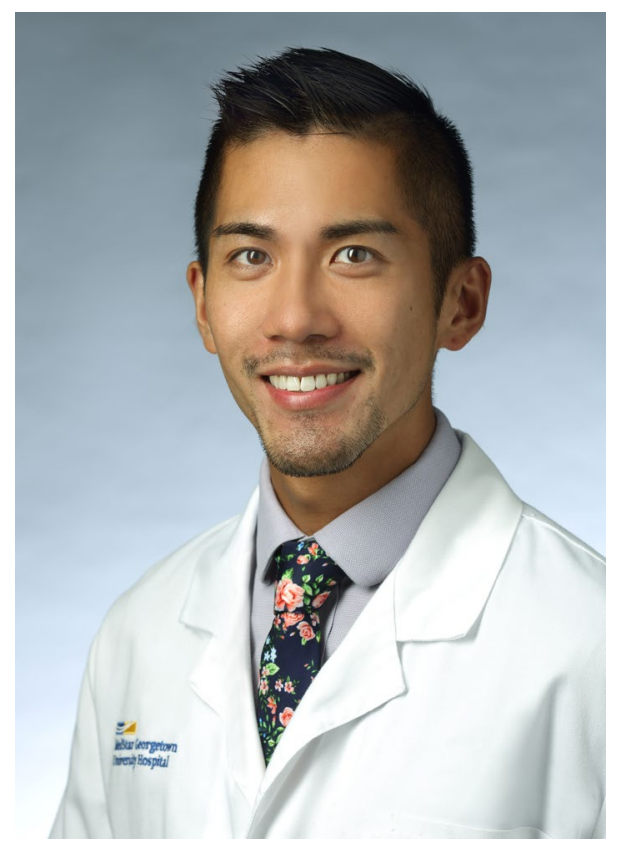

Nikki Duong, MD, completed medical school at the George Washington University School of Medicine and graduated with a distinction in the Research Track. He then went on to complete his Internal Medicine Residency at Georgetown University Medical Center. During his time in residency, he first-authored several peer-reviewed publications and presented at national meetings. He was selected as an AASLD Emerging Liver Scholar and Ambassador and now serves on the Communications Subcommittee of the Liver Transplantation and Surgery Committee. He found his true passion in medical education during his residency and was selected as the 2019 Hugh Hussey recipient by the fourth-year medical students in recognition of his excellence in teaching and mentorship. The faculty also selected him for the William Argy Memorial Housestaff Award for dedication to the students and housestaff in teaching, mentorship, and scholarship. Finally, he was also selected for the Donald Knowlan Award for exemplary qualities of compassion, humor, and encouragement during his residency. Although he went unmatched during his first attempt, he re-applied for a second time and will be a GI fellow at the Virginia Commonwealth University Medical Center in Richmond, Virginia. He plans to become an Academic Transplant Hepatologist with a focus on NAFLD and underserved populations and one day become a Fellowship Program Director. He is currently an Assistant Professor of Medicine/Hospitalist at the Georgetown University Medical Center.

Publisher's Note Springer Nature remains neutral with regard to jurisdictional claims in published maps and institutional affiliations.
Nikki Duong

nduong91@gmail.com

1 Department of Internal Medicine, Georgetown University Hospital, Washington, DC, USA 